\title{
Natural Leishmania (Viannia) spp. infections in phlebotomine sand flies (Diptera: Psychodidae) from the Brazilian Amazon region reveal new putative transmission cycles of American cutaneous leishmaniasis
}

\author{
Adelson Alcimar Almeida de Souza ${ }^{1, \dagger}$, Thiago Vasconcelos dos Santos ${ }^{1}$, Yara Lúcia Lins Jennings ${ }^{1}$, \\ Edna Aoba Yassui Ishikawa ${ }^{2}$, Iorlando da Rocha Barata ${ }^{1}$, Maria das Graças Soares Silva ${ }^{1, \dagger}$, \\ José Aprígio Nunes Lima ${ }^{1}$, Jeffrey Shaw ${ }^{3}$, Ralph Lainson ${ }^{1, \dagger}$, and Fernando Tobias Silveira ${ }^{1,2, *}$ \\ 1 Parasitology Department, Evandro Chagas Institute (Surveillance Secretary of Health, Ministry of Health), \\ Ananindeua, Pará State, Brazil \\ 2 Tropical Medicine Nucleus, Federal University of Pará, Belém, Pará State, Brazil \\ 3 Biomedical Sciences Institute, São Paulo University, São Paulo State, Brazil
}

Received 24 March 2016, Accepted 30 April 2016, Published online 27 May 2016

\begin{abstract}
In Amazonian Brazil the etiological agents of American cutaneous leishmaniasis (ACL) belong to at least seven Leishmania species but little is known about the putative phlebotomine sand fly vectors in different biomes. In 2002-2003 a survey of the phlebotomine fauna was undertaken in the "Floresta Nacional do Tapajós", Belterra municipality, in the lower Amazon region, western Pará State, Brazil, where we recently confirmed the presence of a putative hybrid parasite, $L$. (V.) guyanensis $\times L$. (V.) shawi shawi. Sand flies were collected from Centers for Disease Control (CDC) light traps, Shannon traps and by aspiration on tree bases. Females were dissected and attempts to isolate any flagellate infections were made by inoculating homogenized midguts into Difco $\mathrm{B}^{45}$ medium. Isolates were characterized by monoclonal antibodies and isoenzyme electrophoresis. A total of 9,704 sand flies, belonging to 68 species or subspecies, were collected. Infections were found in the following sand flies: L. (V.) naiffi with Psychodopygus hirsutus hirsutus (1) and Ps. davisi (2); and L. (V.) shawi shawi with Nyssomyia whitmani (3) and Lutzomyia gomezi (1). These results provide strong evidence of new putative transmission cycles for $L$. (V.) naiffi and L. (V.) s. shawi.
\end{abstract}

Key words: Leishmania (Viannia) spp., Phlebotomine sand flies, Natural infections, Amazon region, Pará State, Brazil.

\begin{abstract}
Résumé - Les infections naturelles par Leishmania (Viannia) spp. chez les phlébotomes (Diptera: Psychodidae) de la région amazonienne du Brésil révèlent de nouveaux cycles putatifs de transmission de la leishmaniose cutanée américaine. En Amazonie brésilienne les agents étiologiques de la leishmaniose cutanée américaine (LCA) appartiennent à au moins sept espèces de Leishmania, mais on connaît mal les phlébotomes vecteurs dans les différents biomes. En 2002 et 2003 une enquête sur la faune des phlébotomes a été entreprise dans la « Floresta Nacional do Tapajós », commune de Belterra, dans la région inférieure de l'Amazonie, ouest de l'État du Pará, au Brésil, où nous avons récemment confirmé la présence d'un parasite hybride putatif, $L$. (V.) guyanensis $\times L$. (V.) shawi shawi. Les phlébotomes ont été recueillis dans des pièges lumineux CDC, des pièges Shannon et par aspiration sur la base des arbres. Les femelles ont été disséquées et on a tenté d'isoler les infections par des flagellés en inoculant des mésogastres homogénéisés dans un milieu Difco B45. Les isolats ont été caractérisés par des anticorps monoclonaux et l'électrophorèse des isoenzymes. Un total de 9704 phlébotomes, appartenant à 68 espèces ou sous-espèces, ont été collectés. Des infections ont été trouvées dans les phlébotomes suivants: L. (V.) naiffi avec Psychodopygus hirsutus hirsutus (1) et Ps. davisi (2); L. (V.) shawi shawi avec Nyssomyia whitmani (3) et Lutzomyia gomezi (1). Ces résultats fournissent des preuves solides de nouveaux cycles putatifs de transmission pour $L$. (V.) naiffi et $L$. (V.) s. shawi.
\end{abstract}

\footnotetext{
*Corresponding author: fernandotobias@iec.pa.gov.br; ${ }^{\dagger}$ In memoriam
} 


\section{Introduction}

In the Brazilian Amazon region, American cutaneous leishmaniasis (ACL) is caused by at least seven Leishmania species that are dermotropic in man, namely: Leishmania (Viannia) braziliensis Vianna 1911, L. (V.) guyanensis Floch 1954, L. (Leishmania) amazonensis Lainson and Shaw 1972, L. (V.) lainsoni Silveira et al. 1987, L. (V.) shawi Lainson et al. 1989, L. (V.) naiff Lainson and Shaw 1989, and L. (V.) lindenbergi Silveira et al. 2002 [15, 18]. Human infections with these leishmanial parasites give rise to an extensive array of clinical and immunological manifestations that range from localized cutaneous leishmaniasis (LCL) at the center of the spectrum to mucocutaneous leishmaniasis (MCL) at the hypersensitivity pole and anergic diffuse cutaneous leishmaniasis (ADCL) at the hyposensitivity one $[37,38]$. L. (V.) braziliensis tends to provoke infections with accentuated hypersensitivity (MCL), while in contrast those with $L$. (L.) amazonensis tend toward hyposensitivity (ADCL) [39, 40]. A Leishmania species may be transmitted by different sand fly (Diptera: Psychodidae: Phlebotominae) species in different geographical regions and biomes. L. (V.) braziliensis is a good example of a species that is transmitted by different vectors in different ecological niches throughout the Americas [35, 42]. Most studies are one-off and beyond the immediate study areas, little is known about the range of other vectors that are involved. However, a general picture is emerging of a mosaic of enzootic and zoonotic cycles for a given Leishmania species in different ecological niches that range from primary forest to highly anthropogenic areas [6].

In Brazil, the National Forests (abbreviated in Portuguese as "FLONA" - FLOresta NAcional) are conserved forested areas composed of predominantly native species. The goal is to create and maintain forests that are used for both scientific investigations and different methods of sustainable exploitation of the native flora [7]. These conserved areas contain a rich fauna of insects and mammals that are compatible with the establishment and maintenance of Leishmania life cycles [29]. Brazil has 65 registered FLONAs and 32 are located in the northern region of the country. Of this total 13 FLONAs are located in Pará State and those such as the FLONAs of Altamira, Carajás, Itaituba, and Tapajós are among the largest in the country, each having an area of over 400,000 ha.

The following six dermotropic Leishmania species, L. (V.) braziliensis, L. (V.) guyanensis, L. (L.) amazonensis, L. (V.) lainsoni, L. (V.) shawi shawi, L. (V.) shawi santarensis Jennings, Souza, Ishikawa, Shaw, Lainson \& Silveira 2014 and a putative hybrid parasite, L. (V.) guyanensis/L. (V.) shawi shawi were identified in patients who had contracted the disease in the western region of Pará State [16]. Part of the area is composed of the Tapajós FLONA and some years ago the sand fly fauna was studied in an urban area on the outskirts of Santarém city [8], but there were no data on vector incrimination. The aim of the present study was to identify the phlebotomine sand fly fauna of the Tapajós FLONA, located in the lower Amazon region in western Pará State, Brazil, and to incriminate putative vectors by identifying flagellate infections of female flies.

\section{Materials and methods}

\section{Study area}

The Tapajós FLONA $\left(20^{\circ} 45^{\prime} \mathrm{S} 55^{\circ} 00^{\prime} \mathrm{W}\right)$ (Fig. 1) occupies an area of 545,000 ha of predominantly dense rain forest. The climate is hot and humid with temperature variations between $21^{\circ} \mathrm{C}$ and $31^{\circ} \mathrm{C}$, and over 2,000 mm of rain per year, relative humidity is above $80 \%$ and its altitude varies between 19 and $200 \mathrm{~m}$ above sea level. It straddles the lower Amazon municipalities of Belterra, Rurópolis, and Placas of western Pará State, Brazil. The actual study area was located within the FLONA area of Belterra municipality and situated $15 \mathrm{~km}$ from $\mathrm{km} 67$ of the BR 163 highway [41].

\section{Sand fly collection and identification}

Collections were made on six different occasions during a period of 10 days between 2002 (April, June, September, and November) and 2003 (May and October). Eight Centers for Disease Control (CDC) light traps were set between 18:00 and 06:00 hrs each night at $1.5 \mathrm{~m}$ ground level (6) and at $20 \mathrm{~m}$ in the canopy (2). A light-baited Shannon trap was also used between 18:00 and 20:00 as well as captures form the base of three trees from 07:00 to 09:00 with an aspirator. The sampling effort was calculated for each trapping method by multiplying the number of collections ( 55 for CDC, 52 for Shannon, and 17 for aspiration on tree bases) by exposure time ( $12 \mathrm{~h}$ for CDC and $2 \mathrm{~h}$ for Shannon and $2 \mathrm{~h}$ for aspiration on tree bases). Females were dissected under sterile conditions according to Ryan et al. [35] and the males were stored in 70\% alcohol. All specimens were initially identified according to the pictorial key of Young \& Duncan [51] and allotted to genera in accordance with the taxonomic criteria proposed by Galati [12] using the abbreviation suggested by Marcondes [26]. Material was also mounted in berlese liquid (GBI Laboratories) and deposited in the "Instituto Evandro Chagas" Phlebotominae sand fly collection. Species abundance was expressed for the four surveyed ecotopes (ground, canopy, Shannon, and tree bases collected) with the index of species abundance (ISA) and standard index of species abundance (SISA) as described elsewhere [34].

\section{Identification of Leishmania strains}

The homogenate obtained from the digestive tract of naturally infected females was inoculated into two culture tubes containing Difco $\mathrm{B}^{45}$ media prepared according to Walton et al. [49]. The isolates were characterized with a panel of 23 monoclonal antibodies (B2, B5, B12, B11, B13, B18, B19, CO1, CO2, CO3, D13, L1, LA2, M2, N2, N3, V1, WA2, W1, W2, WH1, VIC.79.3, and T3) according to Shaw et al. [44]. Strains were also characterized phenotypically by isoenzyme electrophoresis for the 6-Phosphogluconate Dehydrogenase ( ${ }_{6} \mathrm{PGDH}, \mathrm{EC}$ 1.1.1. 44) enzymatic system, according to the method described by Miles et al. [27]. The McAb and/or electrophoretic profiles from the Leishmania isolates were compared with those of the World Health Organization 


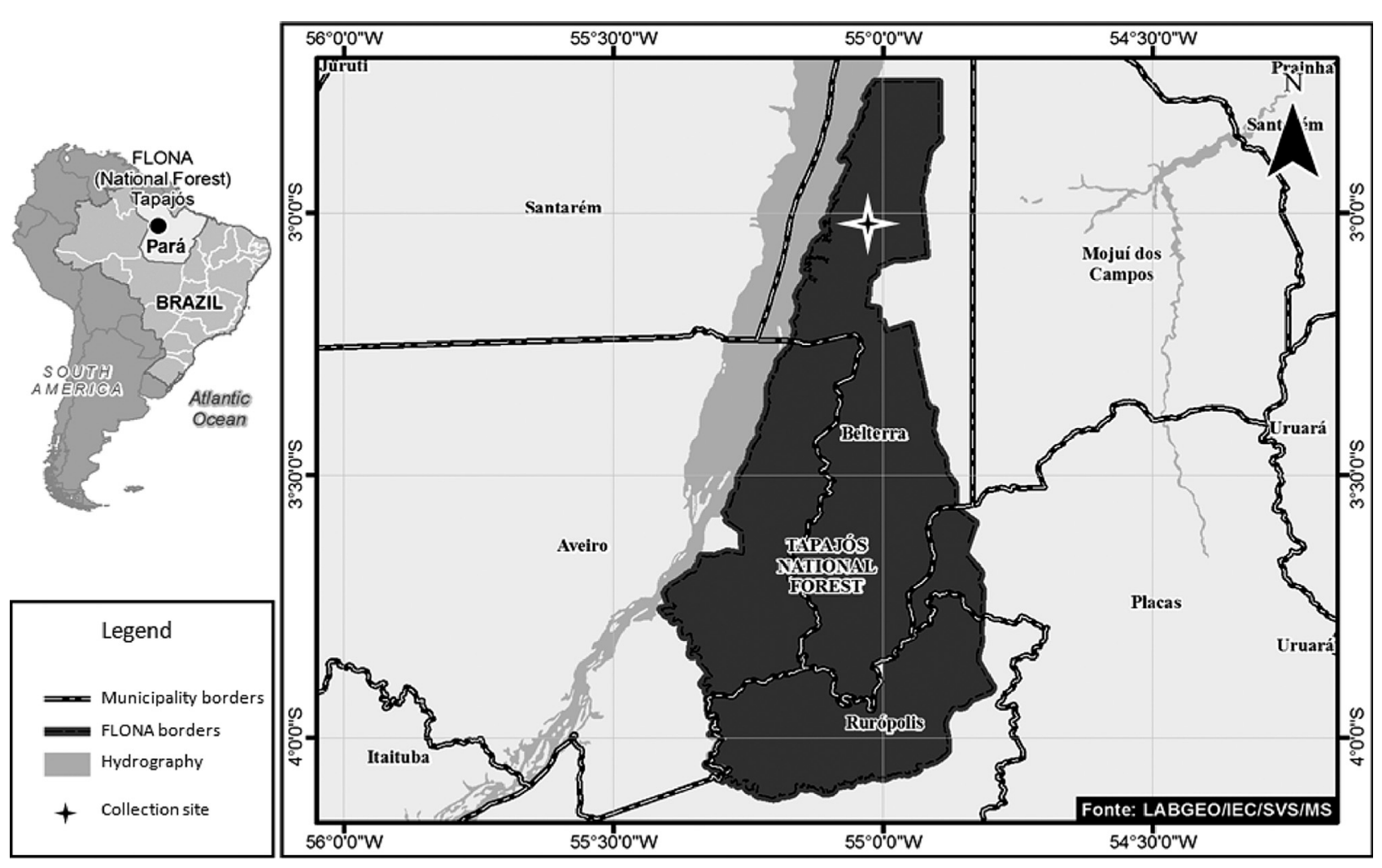

Figure 1. Study area. The location of Tapajós FLONA in the lower Amazon region, western Pará State, Brazil.

(WHO) reference strains maintained in the cryobank of the Leishmaniasis Laboratory "Prof. Dr. Ralph Lainson", as follows: L. (L.) amazonensis (IFLA/BR/67/PH8), L. (V.) braziliensis $(\mathrm{MHOM} / \mathrm{BR} / 75 / \mathrm{M} 2903$, L. (V.) guyanensis (MHOM/BR/ 75/M4147), L. (V.) naiffi (MDAS/BR/79/M5533), L. (V.) lainsoni (MHOM/BR/81/M6426), L. (V.) s. shawi (MCEB/BR/ 84/M8408), and L. (V.) lindenbergi (MHOM/BR/98/16714). A strain of the recently ranked subspecies, L. (V.) shawi santarensis (MHOM/BR/90/M13070), was taken into consideration as a novel Leishmania reference strain, but not included in the electrophoretic run as its ${ }_{6} \mathrm{PGDH}$ profile is the same as that of the $L$. $(V)$ s. shawi WHO reference strain.

\section{Results}

\section{Sand fly fauna}

A total of 9,704 individuals were collected of which 6,179 were females and 3,525 males, belonging to 68 species or subspecies, as shown in Table 1. Most individuals were collected in $660 \mathrm{~h} /$ trap hours in ground level CDCs $(3,909)$, followed by $110 \mathrm{~h}$ Shannon trapping $(3,399), 660 \mathrm{~h} /$ trap canopy CDCs $(1,753)$, and $34 \mathrm{~h}$ of aspiration on tree bases (643).

Fifteen genera were identified and are as follows: Psychodopygus (Ps., 16 spp.), Psathyromyia (Pa., 10 spp.), Evandromyia (Ev., 10 spp.), Nyssomyia (Ny., $6 \quad$ spp.), Micropygomyia (Mi., 5 spp.), Pintomyia (Pi.,4 spp.), Trichopygomyia (Ty., 3 spp.), Lutzomyia (Lu., 3 spp.), Trichophoromyia (Th.,2 spp.), Viannamyia (Vi., 2 spp.), Pressatia (Pr., 2 spp.),
Brumptomyia (Br., 2 spp.), Bichromomyia (Bi., 1 spp.), Migonemyia (Mi., 1 spp.), and Sciopemyia (Sc.,1 spp.).

The most frequent sand fly species found were: the closely related Ps. complexus/Ps. wellcomei (14.3\%, SISA Rank 4th), followed by $N y$. umbratilis (10.0\%, SISA Rank 1st), Th. ubiquitalis (8.1\%, SISA Rank 3rd) and $N y$. whitmani (7.7\% SISA Rank 2nd).

\section{Known vectors}

Twelve species known as incriminated or suspected vectors of ACL agents in Amazonian Brazil were identified with their respective frequency, as follows: Ps. complexus/Ps. wellcomei (1,231 females, 71 Ps. complexus and 88 Ps. wellcomei males), Ny. umbratilis (859 females and 121 males), Ny. whitmani (443 females and 307 males), Ps. davisi (388 females and 107 males), Th. ubiquitalis (227 females and 561 males), Ny. anduzei (162 females and 78 males), Ps. paraensis (175 females and 102 males), Bi. flaviscutellata (112 females and 16 males), Ps. ayrozai (1 female and 2 males), and Ps. squamiventris sensu latu (2 females).

\section{Natural infections}

Natural flagellate infections were found in 18 of 6,179 dissected females (infection rate: $0.29 \%$ ) that belonged to the following eight species (Table 2): $N y$. whitmani (6/486, 3 from CDC ground, 1 from CDC canopy, and 2 from Shannon), Mi. pilosa (4/19, 3 from CDC ground and 1 from CDC 
Table 1. Species composition of the Phlebotominae sand fly fauna of Tapajós National forest (Tapajós FLONA), in the Lower Amazon region, western Pará State, Brazil (2002-2003).

\begin{tabular}{|c|c|c|c|c|c|c|c|c|c|c|c|c|c|c|}
\hline \multirow[t]{2}{*}{$S$} & \multirow[t]{2}{*}{ Species } & \multicolumn{2}{|c|}{ CDC ground } & \multicolumn{2}{|c|}{ CDC canopy } & \multicolumn{2}{|c|}{ Shannon } & \multicolumn{2}{|c|}{ Tree bases } & \multirow[t]{2}{*}{ Total } & \multirow[t]{2}{*}{$\%$} & \multicolumn{3}{|c|}{ Abundance } \\
\hline & & $\mathrm{F}$ & $\mathrm{M}$ & $\mathrm{F}$ & M & $\mathrm{F}$ & $\mathrm{M}$ & $\mathrm{F}$ & $\mathrm{M}$ & & & ISA & SISA & Rank \\
\hline 1 & Ps.complexus/wellcomei* & 59 & $17 / 23$ & 58 & $2 / 3$ & $1114 * *$ & $52 / 62$ & - & - & 1390 & 14.3 & 8.25 & 0.827 & 4 th \\
\hline 2 & Ny. umbratilis* & 173 & 26 & 340 & 63 & 326 & 16 & 20 & 16 & 980 & 10 & 3.25 & 0.946 & $1 \mathrm{st}$ \\
\hline 3 & Th. ubiquitalis* & 170 & 510 & 27 & 28 & 23 & 21 & 7 & 2 & 788 & 8.1 & 7.75 & 0.839 & $3 \mathrm{rd}$ \\
\hline 4 & Ny. whitmani* $(6)$ & $170(3)$ & 66 & $161(1)$ & 210 & $105(2)$ & 2 & 7 & 29 & 750 & 7.7 & 4.25 & 0.922 & $2 \mathrm{nd}$ \\
\hline 5 & Th. castanheirai & 55 & 565 & 6 & 40 & 12 & 8 & - & - & 686 & 7 & 17.75 & 0.601 & 15 th \\
\hline 6 & Ps. davisi* (2) & 63 & 40 & 36 & 5 & $288(2)^{* *}$ & 62 & 1 & - & 495 & 5.1 & 8.75 & 0.815 & 5 th \\
\hline 7 & Mi. rorotaensis & 59 & 21 & 34 & - & 9 & 15 & 45 & 255 & 438 & 4.5 & 10.75 & 0.767 & 7th \\
\hline 8 & Ny. shawi (1) & $94(1)$ & 5 & 99 & 1 & 87 & 3 & - & 1 & 290 & 2.9 & 9.5 & 0.797 & 6 th \\
\hline 9 & Ps. paraensis* & 21 & 15 & 20 & 4 & 134 & 82 & - & 1 & 277 & 2.8 & 13 & 0.714 & 10th \\
\hline 10 & Ps. c. carrerai & 16 & 5 & 48 & 7 & 142 & 47 & - & - & 265 & 2.7 & 20.5 & 0.535 & 18th \\
\hline 11 & Ps. leonidasdeanei & 26 & 6 & 5 & - & $196^{* *}$ & 11 & - & - & 244 & 2.5 & 23.5 & 0.464 & 25 th \\
\hline 12 & $N y$. anduzei* & 26 & 7 & 50 & 69 & 85 & 2 & 1 & - & 240 & 2.4 & 12.25 & 0.732 & 9 th \\
\hline 13 & Ty. longispina & 4 & 216 & 3 & 3 & - & - & 1 & - & 227 & 2.3 & 21.25 & 0.517 & 20 th \\
\hline 14 & Ev. saulensis & 186 & 6 & 12 & - & 4 & - & - & - & 208 & 2.1 & 23.75 & 0.244 & 38 th \\
\hline 15 & Vi. furcata & 67 & 13 & 31 & 38 & 9 & 1 & 13 & - & 172 & 1.7 & 11.75 & 0.744 & 8 th \\
\hline 16 & Ev. infraspinosa (1) & $59(1)$ & 91 & 12 & - & 5 & 2 & - & - & 169 & 1.7 & 23.25 & 0.47 & 24 th \\
\hline 17 & Ps. corossoniensis & 29 & - & 7 & - & 120 & - & - & - & 156 & 1.6 & 23.75 & 0.458 & 26th \\
\hline 18 & Ev. campbelli & 2 & 137 & 2 & 1 & - & 1 & 3 & - & 146 & 1.5 & 19.5 & 0.559 & 16th \\
\hline 19 & Lu. gomezi (1) & 82 & 7 & 36 & 2 & $15(1)$ & - & 2 & - & 144 & 1.4 & 13.5 & 0.702 & 11 th \\
\hline 20 & Pi. damascenoi & 32 & - & 13 & - & 7 & 1 & 8 & 67 & 128 & 1.3 & 14.25 & 0.684 & 12 th \\
\hline 21 & Bi. flaviscutellata* & 61 & 13 & 23 & - & 24 & 3 & 4 & - & 128 & 1.3 & 16.25 & 0.636 & 14 th \\
\hline 22 & Ps. h. hirsutus (1) & 9 & 7 & $34(1)$ & 2 & 57 & 17 & - & - & 126 & 1.2 & 15.75 & 0.648 & 13th \\
\hline 23 & Ty. dasypodogeton & 79 & 24 & 7 & 3 & 7 & 1 & 4 & 1 & 126 & 1.2 & 23.75 & 0.458 & 26th \\
\hline 24 & Ny. richardwardi & 23 & 22 & 10 & - & $51 * *$ & 12 & - & - & 118 & 1.2 & 22.5 & 0.488 & 23th \\
\hline 25 & Ny. antunesi & 50 & 2 & 37 & - & 6 & - & - & - & 95 & 0.9 & 23.75 & 0.458 & 26th \\
\hline 26 & Br. avellari & - & 78 & - & 9 & - & 2 & - & - & 89 & 0.9 & 26.5 & 0.392 & 28th \\
\hline 27 & Mi. trinidadensis & 16 & 3 & 9 & 1 & 1 & - & 9 & 47 & 86 & 0.8 & 20 & 0.547 & 17 th \\
\hline 28 & Ps. claustrei & 5 & 2 & 7 & - & 31 & 15 & - & - & 60 & 0.6 & 28.5 & 0.345 & 32th \\
\hline 29 & $B r$. spp. & 43 & - & 10 & - & 1 & - & - & - & 54 & 0.5 & 20.75 & 0.529 & 19th \\
\hline 30 & Pa. dendrophyla & 2 & 1 & 11 & 2 & 3 & 4 & 11 & 19 & 53 & 0.5 & 21.75 & 0.505 & 21th \\
\hline 31 & Pa. aragaoi & 17 & 25 & 3 & 6 & - & - & - & - & 51 & 0.5 & 31 & 0.285 & 35 th \\
\hline 32 & Sc. sordellii (2) & $32(2)$ & 3 & 2 & 5 & 1 & 5 & - & - & 48 & 0.4 & 27.75 & 0.363 & 29 th \\
\hline 33 & Pr. trispinosa & - & 24 & - & 4 & - & 14 & - & - & 42 & 0.4 & 28 & 0.357 & 30th \\
\hline 34 & Mg. migonei & 6 & 5 & 8 & 16 & - & 1 & - & - & 36 & 0.3 & 29.5 & 0.321 & 33th \\
\hline 35 & Ev. evandroi & 17 & - & 18 & - & 1 & - & - & - & 36 & 0.3 & 30.25 & 0.303 & 34 th \\
\hline 36 & Vi. tuberculata & 18 & 1 & 7 & 3 & 5 & - & - & 1 & 35 & 0.3 & 22 & 0.5 & 22 th \\
\hline 37 & Ps. bispinosus & 2 & - & 3 & - & 26 & 4 & - & - & 35 & 0.3 & 31.25 & 0.279 & 36th \\
\hline 38 & Pa. scaffi & 3 & - & - & - & 1 & 2 & - & 24 & 30 & 0.3 & 29.5 & 0.321 & 33th \\
\hline 39 & Pa. dreisbachi & 22 & - & 5 & - & - & & 2 & - & 29 & 0.2 & 26.5 & 0.392 & 28th \\
\hline 40 & Pa. shannoni & - & 1 & 1 & - & 6 & 1 & 10 & 8 & 27 & 0.2 & 25.5 & 0.416 & 27 th \\
\hline 41 & Pi. serrana & 3 & 13 & 1 & - & 1 & - & - & 2 & 20 & 0.2 & 25.5 & 0.416 & 27 th \\
\hline 42 & Lu. carvalhoi & 13 & - & 4 & 2 & - & - & - & 1 & 20 & 0.2 & 28.25 & 0.351 & 31 th \\
\hline 43 & Ps. geniculatus & 1 & - & 7 & 1 & 11 & - & - & - & 20 & 0.2 & 31.75 & 0.267 & 37 th \\
\hline 44 & Mi. pilosa (4) & $14(3)$ & - & 2 & - & - & - & $3(1)$ & - & 19 & 0.1 & 28.5 & 0.345 & 32 th \\
\hline 45 & Mi. oswaldoi & 11 & - & 1 & - & - & & 3 & - & 15 & 0.1 & 28.5 & 0.345 & 32 th \\
\hline 46 & Ev. sericea & 8 & 7 & - & - & - & - & - & - & 15 & 0.1 & 29.5 & 0.321 & 33th \\
\hline 47 & Pa. lutziana & - & 10 & 3 & 2 & - & - & - & - & 15 & 0.1 & 39.75 & 0.077 & 50 th \\
\hline 48 & Ps. amazonensis & - & - & - & 2 & 7 & 2 & - & 1 & 12 & 0.1 & 37.75 & 0.125 & 43th \\
\hline 49 & Ty. trichopyga & 9 & - & - & - & - & - & 1 & 1 & 11 & 0.1 & 33.75 & 0.22 & 39th \\
\hline 50 & Pa. punctigeniculata & - & - & - & - & - & 1 & 3 & 5 & 9 & - & 31.75 & 0.267 & 37 th \\
\hline 51 & Br. travassosi & - & 6 & - & 1 & - & - & - & - & 7 & - & 37.75 & 0.125 & 43th \\
\hline 52 & Mi. longipennis & 5 & - & 1 & - & - & - & - & - & 6 & - & 38 & 0.119 & 44th \\
\hline 53 & Pi. nevesi & 4 & - & 1 & - & - & - & - & - & 5 & - & 38.25 & 0.113 & 45 th \\
\hline 54 & Pa. servulolimai & - & 3 & - & - & - & 2 & - & - & 5 & - & 39 & 0.095 & 47 th \\
\hline 55 & Ev. bacula & 2 & 1 & - & - & 2 & - & - & - & 5 & - & 39 & 0.095 & 47 th \\
\hline 56 & Ev. begonae & 2 & - & - & 2 & - & - & - & - & 4 & - & 35.25 & 0.184 & 40th \\
\hline 57 & Pr. triacantha & 3 & - & - & - & - & - & 1 & - & 4 & - & 38.5 & 0.107 & 46th \\
\hline 58 & Ps. ayrozai* & 1 & 2 & - & - & - & - & - & - & 3 & - & 42.25 & 0.017 & 52 th \\
\hline
\end{tabular}


Table 1. (continued)

\begin{tabular}{|c|c|c|c|c|c|c|c|c|c|c|c|c|c|c|}
\hline \multirow[t]{2}{*}{$S$} & \multirow[t]{2}{*}{ Species } & \multicolumn{2}{|c|}{ CDC ground } & \multicolumn{2}{|c|}{ CDC canopy } & \multicolumn{2}{|c|}{ Shannon } & \multicolumn{2}{|c|}{ Tree bases } & \multirow[t]{2}{*}{ Total } & \multirow[t]{2}{*}{$\%$} & \multicolumn{3}{|c|}{ Abundance } \\
\hline & & $\mathrm{F}$ & M & $\mathrm{F}$ & M & $\mathrm{F}$ & M & $\mathrm{F}$ & M & & & ISA & SISA & Rank \\
\hline 59 & Pa. abonnenci & - & - & - & - & - & - & - & 2 & 2 & - & 35.75 & 0.172 & $\overline{41 \text { th }}$ \\
\hline 50 & Ev. wilsoni & - & 2 & - & - & - & - & - & - & 2 & - & 42.5 & 0.011 & 53th \\
\hline 61 & Ps. s. squamiventris* & - & - & - & - & 1 & - & - & - & 1 & - & 36 & 0.166 & 42 th \\
\hline 62 & Lu. spatotrichia & 1 & - & - & - & - & - & - & - & 1 & - & 39.25 & 0.089 & 48th \\
\hline 63 & Pa. inflata & - & - & 1 & - & - & - & - & - & 1 & - & 40 & 0.071 & 51 th \\
\hline 64 & Pi. monticola & - & - & - & - & - & - & 1 & - & 1 & - & 40 & 0.071 & 51th \\
\hline 65 & Ev. monstruosa & 1 & - & - & - & - & - & - & - & 1 & - & 42.75 & 0.005 & 54 th \\
\hline 66 & Ev. pinottii & 1 & - & - & - & - & - & - & - & 1 & - & 42.75 & 0.005 & 54 th \\
\hline 67 & Ps. lainsoni & - & - & - & - & 1 & - & - & - & 1 & - & 42.75 & 0.005 & 54 th \\
\hline \multirow[t]{2}{*}{68} & Ps. s. maripaensis & 1 & - & - & - & - & - & - & - & 1 & - & 42.75 & 0.005 & 54th \\
\hline & Total & 1878 & 2031 & 1216 & 537 & 2925 & 474 & 160 & 483 & 9704 & & & & \\
\hline
\end{tabular}

S: Taxa; F: Females; M: Males; ISA: Index of Species Abundance; SISA: Standard Index of Species Abundance; ${ }^{*}$ Species already associated to American cutaneous leishmaniasis agents in the Amazon region;

** Some specimens found attempting to bit collectors; $(n)$ Number of individuals found with natural infection by flagellates; $\mathrm{n} / \mathrm{n}$ Expressed number for males of Ps. complexus and Ps. wellcomei, respectively.

Table 2. Natural Leishmania (Viannia) spp. infections in phlebotomine sand flies isolated and characterized by monoclonal antibodies.

\begin{tabular}{|c|c|c|c|c|c|c|}
\hline $\mathrm{N}$ & Sand fly species & Collection & Development & Result & MCAb reaction-profile & WHO code \\
\hline 1 & Ps. h. hirsutus & CDC canopy & Peripylaric & Leishmania (Viannia) naiffi & $\mathrm{B} 2, \mathrm{~B} 12, \mathrm{~L} 1, \mathrm{~N} 2, \mathrm{~N} 3$ & IHIR/BR/2002/M20906 \\
\hline 2 & Ps. davisi & Shannon & Peripylaric & L. $(V$.$) naiffi$ & $\mathrm{B} 2, \mathrm{~B} 12, \mathrm{~L} 1, \mathrm{~N} 2, \mathrm{~N} 3$ & IDAV/BR/2002/M20905 \\
\hline 3 & Mi. pilosa & CDC ground & Peripylaric & negative/contamined & - & - \\
\hline 4 & Ny. whitmani & CDC ground & Peripylaric & L. (V.) shawi shawi & $\mathrm{B} 2, \mathrm{~B} 12, \mathrm{~L} 1$ & IWHI/BR/2002/M21354 \\
\hline 5 & Mi. pilosa & CDC ground & Peripylaric & negative/contamined & - & - \\
\hline 6 & Ny. whitmani & Shannon & Peripylaric & negative/contamined & - & - \\
\hline 7 & Ny. whitmani & Shannon & Peripylaric & negative/contamined & - & - \\
\hline 8 & Sc. sordellii & CDC ground & Peripylaric & non Leishmania Trypanosomatidae & - & ISOR/BR/2002/M21358 \\
\hline 9 & Mi. pilosa & CDC ground & Hipopylaric & negative/contamined & - & - \\
\hline 10 & Mi. pilosa & Tree bases & Hipopylaric & negative/contamined & - & - \\
\hline 11 & Ny. shawi & CDC ground & Peripylaric & negative/contamined & - & - \\
\hline 12 & Sc. sordellii & CDC ground & Peripylaric & negative/contamined & - & \\
\hline 13 & Ps. davisi & Shannon & Peripylaric & L. (V.) naiffi & $\mathrm{B} 2, \mathrm{~B} 12, \mathrm{~L} 1, \mathrm{~N} 2, \mathrm{~N} 3$ & IDAV/BR/2003/M21903 \\
\hline 14 & Ny. whitmani & CDC ground & Peripylaric & negative/contamined & - & - \\
\hline 15 & Ev. infraspinosa & CDC ground & Peripylaric & negative/contamined & - & - \\
\hline 16 & Ny. whitmani & CDC ground & Peripylaric & L. (V.) s. shawi & $\mathrm{B} 2, \mathrm{~B} 12, \mathrm{~L} 1$ & IWHI/BR/2003/M22342 \\
\hline 17 & Ny. whitmani & CDC canopy & Peripylaric & L. (V.) s. shawi & B2, B12, L1 & IWHI/BR/2003/M22341 \\
\hline 18 & Lu. gomezi & Shannon & Peripylaric & L. (V.) s. shawi & $\mathrm{B} 2, \mathrm{~B} 12, \mathrm{~L} 1$ & IGOM/BR/2003/M22340 \\
\hline
\end{tabular}

McAb: Monoclonal Antibody; WHO: World Health Organization.

canopy), Ps. davisi (2/388, from Shannon), Sc. sordellii (2/35, from CDC ground), Lu. gomezi (1/135, from Shannon), Ps. $h$. hirsutus (1/100, from CDC canopy), Ev. infraspinosa (1/76, from CDC ground), and $N y$. shawi (1/280, from CDC ground).

Flagellates from eight infections were successfully isolated in culture media (Difco $\mathrm{B}^{45}$ ) and eight were Leishmania spp. and one was a non-Leishmania Trypanosomatidae parasite. Four strains from $\mathrm{Ny}$. whitmani (2 from CDC ground and 1 from CDC canopy) and Lu. gomezi (1 from Shannon) were characterized as L. (V.) s. shawi and 3 from Ps. h. hirsutus (1 from CDC canopy) and Ps. davisi (2 from Shannon) were identified as $L$. (V.) naiffi.

The monoclonal antibody $(\mathrm{McAb})$ reaction profiles of both characterized L. (V.) spp. (L. s. shawi and L. naiffi) were identical to those of their WHO reference strains, presenting positive reactions to $\mathrm{McAb} \mathrm{B} 2, \mathrm{~B} 12$, and $\mathrm{L} 1$ (McAb reaction profile IV) for $L .($ V.) s. shawi and B2, B12, L1, N2, and N3 for $L$. (V.) naiffi, respectively.

The identity of $L$. (V.) $s$. shawi strains was confirmed by comparing their ${ }_{6} \mathrm{PGDH}$ profile with a strain isolated from Ny. whitmani whose isoenzymatic profile was identical to that of the L. (V.) s. shawi WHO reference strain (Fig. 2).

\section{Discussion}

There are few studies that describe the phlebotomine sand fly fauna of Brazilian FLONA(s), especially in the Amazon region. These environments have an exuberant biodiversity that favors a variety of microclimatic conditions that are suitable for the development of immature sand flies and a rich vertebrate fauna that serves as a source of food for adult females. For example, 69 sand fly species have been recorded [46] in 


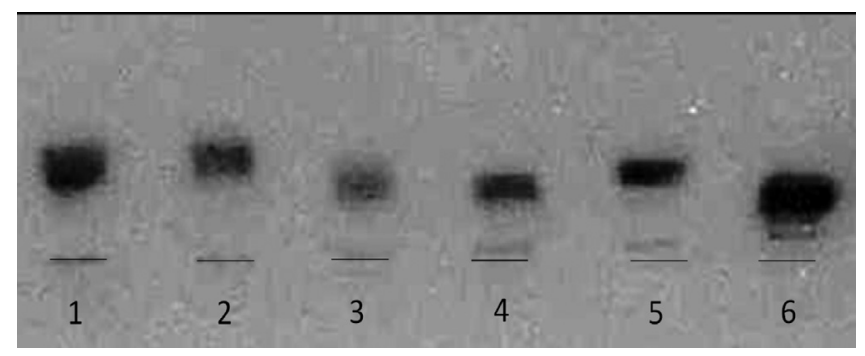

Figure 2. ${ }_{6} \mathrm{PGHD}$ isoenzyme electrophoresis analysis for identifying a Leishmania spp. strain isolated from $N y$. whitmani collected in the Tapajós FLONA (Belterra municipality), lower Amazon region, western Pará State, Brazil. From left to right: $1-L$. $($ V.) braziliensis (MHOM/BR/75/M2903), 2 - L. (V.) guyanensis (MHOM/BR/75/ M4147), 3 - IWHI/BRA/2002/M21354, 4 - L. (V.) s. shawi (MCEB/ BR/84/M8408), 5 - L. (V.) naiffi (MDAS/BR/79/M5533), 6 - L. (V.) lindenbergi (MHOM/BR/98/16714).

the "Serra dos Carajás" (southeast Pará State) in which the Tapirapé-Aquiri FLONA is located.

There is an inevitable bias in the species composition of catches according to the trapping method. One of the challenges is to assess which method best reflects the composition of the sand fly fauna in a given biome or ecological niche. For instance, the three dominant species in CDC ground traps were Ny. umbratilis, Th. ubiquitalis, and Ny. whitmani yet in the Shannon trap Ps. wellcomei/complexus females dominated. However, although the Shannon trap is a light trap, there is a human bait element of the person who is collecting the flies as they alight on the trap's surface material. Of the total females captured in ground level CDCs, $3.1 \%$ of the females were Ps. wellcomei/complexus while in the Shannon trap these same females represented $38 \%$. In the CDC ground level trap, $12 \%$ of the female flies belonged to the genus Psychodopygus and $28.5 \%$ to the genus Nyssomyia but in the Shannon trap $72.6 \%$ of the females were Psychodopygus and $22.4 \%$ were Nyssomyia. The question is: which trapping method gave the best representation of the leishmaniasis vectors in our study area? It is tempting to say that without a doubt it was the Shannon trap in which Psychodopygus species were overwhelmingly dominant, especially Ps. complexus/Ps. wellcomei. However, no infections were found in 1,231 females of this group and 4 of the 7 Leishmania infections were found in flies that did not belong to this genus. Also, none of the infections belonged to the braziliensis complex and in a recent study [16] only $9.4 \%$ of the patients from this general area were infected with $L$. (V.) braziliensis. Overall, we captured 12 phlebotomine species that have been implicated as vectors of ACL agents in the Brazilian Amazon region. Their importance in relation to the Tapajós FLONA area is discussed below.

The complex of two cryptic species belonging to the chagasi series, Ps. complexus/Ps. wellcomei, was the most frequent taxa in the collections. Ps. wellcomei is undoubtedly considered the major vector of $L$. (V.) braziliensis in the Carajás region of the Brazilian Amazon [20, 32]. However, Ps. complexus, a closely related sand fly morphologically distinguishable from the former only by the males was also associated with the transmission of this parasite in areas where
Ps. wellcomei is absent [45]. Unfortunately, due to their sympatric occurrence in the Tapajós FLONA and the lack of technical conditions for characterization of these specimens at specific level, it was not possible to avoid ambiguous identification, and thus they have been regarded in this study as a single species complex. Curiously, although 1,231 females of $P S$. complexus/Ps. wellcomei were dissected to search for natural infection by their associated parasite $L$. (V.) braziliensis, none was found with flagellates. This leads us to suggest that the Ps. complexus/Ps. wellcomei females are feeding on animals that are not reservoirs of $L$. (V.) braziliensis or that these parasite reservoirs are perhaps present in small numbers, resulting in only sporadic transmission to man. Identification of the males suggests that these two species were present in similar numbers. However, in the Carajás, seven ecotopes were sampled with CDCs and in none were the proportion of males of the two species similar [32].

The second most frequent vector found in the Tapajós FLONA was Ny. umbratilis, which is considered to be the principal vector of $L$. (V.) guyanensis ACL in the region to the north of the Amazon River [1, 2, 22, 33]. Fraiha et al. [11], collecting anthropophilic sand flies along the Transamazonian Highway, have found this species in localities such as $\mathrm{Km}$ 211 of the Santarém-Cuiabá Highway, in the nearby area of Tapajós FLONA. More recently, Feitosa \& Castellón [8] registered $N y$. umbratilis as the fourth most frequent sand fly species in the outskirts of Santarém municipality. The closely related species, Ny. anduzei, was also identified in the Tapajós FLONA, but in low numbers and is also considered as a vector of L. (V.) guyanensis ACL [21,50].

Early data on ACL etiology in the lower Amazon region linked Ny. umbratilis to L. (V.) guyanensis and Jennings et al. [16] recorded the presence of two isolates of this same parasite from Santarém municipality in the "leishmanian bridging zone" south of the Amazon River. No natural infection was found in a considerable number of Ny. umbratilis females but on epidemiological grounds, it must be considered as a potentially important vector in the studied area.

Th. ubiquitalis was the third most frequent vector found. Again no infections were found but Jennings et al. [16] identified 6 ACL L. (V.) lainsoni infections in patients from the same region. So far Th. ubiquitalis is the only known vector of $L$. (V.) lainsoni in Brazil $[25,36]$ so its presence in large numbers is consistent with the number of ACL cases with this parasite.

Nyssomyia whitmani deserves special attention since it was the fourth commonest vector species and 1\% (5/486) of the females had flagellates. Four Leishmania strains were successfully isolated and characterized as $L$. (V.) $s$. shawi, reinforcing the well-known role of $N y$. whitmani in the transmission of this parasite in the lower Amazon region of western Pará as well as in eastern Amazonian areas [23, 29]. All L. (V.) s. shawi strains characterized in this study were from $N y$. whitmani sand flies collected by CDC light traps at ground and canopy level. The monoclonal antibody profile of these strains was identical to that of the WHO reference strain isolated from the nonhuman primate Sapajus apella (syn. Cebus apella) Linnaeus 1758. No natural infections of $L$. (V.) s. santarensis were found in $N y$. whitmani or any other sand fly species so its vector(s) remains unknown. 
Leishmania ( $V$.) guyanensis has been recorded in $N y$. whitmani from captures in localities of the northern bank of the Amazon River, such as Monte Dourado (Pará State) $[22,35]$ and Serra do Navio (Amapá State) (Souza, unpublished observation), but its role in the epidemiology of Guianan ACL needs to be evaluated in greater detail and will be discussed in our further publication. However, the fact that it has been found naturally infected with two different parasites of the guyanensis complex adds weight to the hypothesis that the putative hybrid parasite, L. (V.) guyanensis/L. (V.) s. shawi, is the result of genetic exchange between these two closely related Leishmania species that share the same sand fly vector, $N y$. whitmani [16].

Besides being found in Ny. whitmani, L. (V.) s. shawi was also isolated from one specimen of $L u$. gomezi from the Shannon trap. This species is implicated as a vector of $L$. (V.) panamensis in Panama [47] and other Latin American countries $[9,48]$. It is conceivable that $L u$. gomezi participates in the transmission of ACL in the Brazilian Amazon region as well as indicating a permissiveness of $L$. (V.) s. shawi in relation to its vectors. The association of this fly with arboreal animals, that are the reservoirs of this parasite, is also supported by the identification [10] of Endotrypanum spp., in a specimen of this fly captured in Rondônia [13].

Our finding of L. (V.) naiffi in Ps. h. hirsutus (1) and Ps. davisi (2), neither of which is considered as potential vectors of this viannian [29, 31], raises a number of intriguing possibilities. Its recognized vectors are from the Psychodopygus panamensis series, Ps. paraensis, Ps. ayrozai [3, 19] as well as suspected vectors within the chagasi series, such as $P s$. squamiventris s.l. [14]. All these species were present in small numbers in our collections, suggesting that the enzootic cycle is present in the primary forest where it is being transmitted by various Psychodopygus species. However, Jennings et al. [16] failed to find $L$. (V.) naiffi in patients from the general area. Although Ps. h. hirsutus was uncommon in our catches, Ps. davisi was the third most frequent species in our Shannon trap catches. This suggests that transmission to man may be more frequent than is indicated and that the low-frequency figures $[4,16,24,28]$ could be partly explained by the benign nature of $L .(V$.$) naiffi ACL.$

In the 1980s trypanosomatid infections were found in $3 P S$. h. hirsutus captured in the Pará municipality of Tucuruí [35], and 1 from the Minas Gerais municipality of Além Paraíba [30]. At the time no specific monoclonal antibodies for $L$. (V.) naiffi were available and the parasites were identified as belonging to the braziliensis complex. However, a recent revision of these results shows that the $\mathrm{B} 2$ and $\mathrm{B} 12$ profiles of the four strains are identical to those of $L$. (V.) naiffi (Shaw unpublished observation). Five years later flagellates were found in two specimens of Ps. h. hirsutus from the Rondônia municipalities of Cacaulândia and Campo Novo [13]. Their serodemic profile, using the same panel of monoclonal antibodies as the present study, indicated that the parasites were $L$. (V.) naiffi. All these results suggest that Ps. $h$ hirsutus is an important vector of $L$. (V.) naiffi throughout the forested regions of Brazil.

The fact that Ps. $h$ hirsutus was collected in canopy CDC traps, including an infected one, might be interpreted as circumstantial evidence of an $L$. (V.) naiffi arboreal enzootic cycle involving other reservoirs. But $L$. (V.) naiffi's accepted reservoir is the nine-banded armadillo, Dasypus novemcinctus Linnaeus 1758 , which is an obligatory terrestrial mammal. On the other hand, it could just be a natural vertical migration of flies that became infected on the ground. An example of this is the vertical migration of $N y$. umbratilis that becomes infected from the arboreal two-toed sloth but transmission to man occurs at ground level when the fly descends from the canopy during the day [33]. Using the k-DNA PCR technique, Cassia-Pires et al. [5] found evidence of $L$. ( $V$.) naiffi in the caviomorph rodent Thrichomys pachyurus Wagner, 1845 (syn. T. fosteri) that lives in open areas of the caatinga and cerrado. Armadillos also live in this habitat so flies that fed on armadillos could have infected these rodents, or there is a separate cycle in these rats.

Psychodopygus davisi has already been incriminated as a potential vector of zoonotic $L$. $(V$.$) braziliensis ACL in$ Rondônia State [14] and more recently in the Tapirapé-Aquiri FLONA, Pará State [46]. However, the present finding of two infections of $P$ s. davisi, one of which proved to be $L$. (V.) naiffi (Shannon collections), is in accordance with Gil et al. [13] who also found $P s$. davisi to be naturally infected by $L$. (V.) naiffi in Rondônia State. These results strongly support the hypothesis that $P$ s. davisi is involved in the transmission of $L$. (V.) naiffi in both the eastern and western regions of the Brazilian Amazon.

Seven criteria based on epidemiological, entomological, parasitological, and mathematical data $[17,31]$ have been suggested for defining vector status. In our opinion the finding of diverse natural flagellate infections, on more than one occasion in Ps. davisi that were identical to the Dasypus novemcintus reference strain, and this fly's epidemiological associations, achieves four of seven criteria. We therefore conclude that Ps. davisi should be regarded as a new suspected vector of the $L$. (V.) naiffi enzootic life cycle in the lower Amazon region.

The SISA ranking approximated a ranking based on the total number of individuals collected with a minor exception as PS. wellcomei/complexus had a SISA ranking at 4th but it was 1 st based on total numbers, probably biased due to the absence of this species in one out of four studied ecotopes (tree bases). However, all Leishmania infections, except one in Ps. h. hirsutus, occurred in flies ranked 10th or above. This suggests that the SISA ranking based on the overall number of flies captured in all traps gives a more accurate indication of the vectorial importance of each species than a simple ranking based on total numbers. In this respect it is interesting to note that of 43 strains isolated from patients who contracted the disease in the region of the study area, 11 were $L$. $(V$. braziliensis, 6 were L. (V.) lainsoni, 2 were $L$. (L.) amazonensis, and 35 were species belonging to the guyanensis complex [16]. The latter are transmitted by two species of flies, $N y$. umbratilis and $N y$. whitmani, whose SISA ranking in our study is, respectively, 1 and 2. L. (V.) naiff's vector SISA ranking was 3 rd but no human cases were recorded. However, the low pathogenicity of this parasite is thought to relate to cases being underreported. The species ranked 5th and 13th, Ps. davisi and Ps. $h$. hirsutus, are considered as vectors of $L$. (V.) lainsoni that was the 3rd most common parasite found in man after $L$. ( $V$. $)$ 
braziliensis, but there was no statistical difference between the numbers of cases of the two parasites.

Flagellate infections in Ev. infraspinosa and Sc. sordellii (syn. Lu. nordestina) were not isolated but past experience suggests that they have no importance in the epidemiology of leishmaniasis. These infections were trypanosomes and have previously been reported in these two sand fly species as far apart as Pará State and Rondônia [13, 35, 43]. The rondonian Ev. infraspinosa and Sc. sordellii infections proved to be the insect stage of a new clade of trypanosomes found in terrestrial anurans [10].

Our study has confirmed the presence of rich and varied anthropophilic sand fly fauna in the Tapajós FLONA that includes five sand fly species that are associated with Leishmania transmission. The finding of infections adds weight to the importance of Ps. h. hirsutus and Ps. davisi as vectors of $L$. (V.) naiffi, whereas the transmission of $L$. (V.) s. shawi is strongly associated with $N y$. whitmani. The absence of Leishmania infections in Ps. complexus/Ps. wellcomei, Ny. umbratilis, and Th. ubiquitalis in no way diminishes their potential participation in the transmission of ACL in the lower Amazon region in western Pará State, especially as $L$. (V.) braziliensis, L. (V.) guyanensis, and $L$. (V.) lainsoni have been recorded in humans in the region [16]. Our results indicate the presence of complex and poorly understood ACL epidemiologies that are associated with very diverse sand fly fauna. Under these conditions humans can potentially become infected with more than one Leishmania species that may or may not result in different diseases.

Acknowledgements. The authors wish to thank Angelo de Lima Francisco and Nely Alves da Silva (Tapajós FLONA), Wanderley Rocha and Paulo Moutinho (Seca Floresta Project - IPAM), Jorge Eilman (Funasa), Bethany Reed, and Rosilene Santana (LBA) for their help in the field work; Suêd Freitas Silva and Raimundo Nonato Barbosa Pires (IEC) for their technical support in the field and laboratory work; and Instituto Evandro Chagas (IEC) for the financial support.

\section{References}

1. Arias JR, Freitas RA. 1977. Flebótomos da Amazônia Central do Brasil. I. Resultados obtidos das capturas feitas com isca humana e eqüina. Acta Amazonica, 7, 507-527.

2. Arias JR, Freitas RA. 1978. Sobre os vetores da Leishmaniose cutânea na Amazônia Central do Brasil. II. Incidência de flagelados em flebótomos silvaticos. Acta Amazonica, 8, 387-396.

3. Arias JR, Miles MA, Naiff RD, Póvoa MM, de Freitas RA, Bincardi CB, Castellón EG. 1985. Flagellate infections of Brazilian sand flies (Diptera: Psychodidae): Isolation in vitro and biochemical identifications of Endotrypanum and Leishmania. American Journal of Tropical Medicine and Hygiene, 34, 1098-1108.

4. Campos MB, Gomes CMC, de Souza AAA, Lainson R, Corbett CEP, Silveira FT. 2008. In vitro infectivity of species of Leishmania (Viannia) responsible for American cutaneous leishmaniasis. Parasitology Research, 103, 771-776.

5. Cassia-Pires R, Boite MC, D'Andrea PS, Herrera HM, Cupolillo E, Jansen AM, Roque AL. 2014. Distinct Leishmania species infecting wild caviomorph rodents (Rodentia: Hystricognathi) from Brazil. PLoS Neglected Tropical Diseases, 8, e3389.

6. Castellón EG. 2009. Lutzomyia sand flies in the Brazilian Amazon Basin (Diptera: Psychodidae). Instituto Nacional de Pesquisas da Amazônia: Manaus, 202 p.

7. Federal Law n. 9.985, from 07/18/2000. Regulates the article $n$. $225, \S 1^{\circ}$, item I, II, III, and VII of the Brazilian Federal Constitution, establish the National System of Nature Conservation Units and gives other provisions.

8. Feitosa MAC, Castellón EG. 2009. Flebotomíneos (Diptera: Psychodidae) na periferia de Santarém (PA). Estratificação horizontal e fatores agravantes para transmissão domiciliar de leishmanioses. Revista Colombiana de Ciencia Animal, 1, 222-239.

9. Feliciangeli MD, Rabinovich J. 1998. Abundance of Lutzomyia ovallesi but not Lu. gomezi (Diptera: Psychodidae) correlated with cutaneous leishmaniasis incidence in north-central Venezuela. Medical and Veterinary Entomology, 12, 121-131.

10. Ferreira RC, De Souza AA, Freitas RA, Campaner M, Takata CS, Barrett TV, Shaw JJ, Teixeira MM. 2008. A phylogenetic lineage of closely related trypanosomes (Trypanosomatidae, Kinetoplastida) of anurans and sand flies (Psychodidae, Diptera) sharing the same ecotopes in Brazilian Amazonia. Journal of Eukaryotic Microbiology, 55, 427-435.

11. Fraiha H, Ward RD, Shaw J, Lainson R. 1978. Fauna antropófila de flebótomos (Diptera: Psychodidae) da rodovia transamazônica, Brasil. Boletin de la Oficina Sanitaria Panamericana, 84, 134-140.

12. Galati EAB. 2003. Morfologia e Taxonomia: Morfologia, terminologia de adultos e identificação táxons da América, in Flebotomíneos do Brasil, Rangel EF, Lainson R, Editors. Fiocruz: Rio de Janeiro. p. 53-175.

13. Gil LH, Basano AS, Souza AA, Silva MG, Barata I, Ishikawa EA, Camargo LM, Shaw JJ. 2003. Recent observations on the sand fly (Diptera: Psychodidae) fauna of the state of Rondônia, western Amazonia, Brazil: the importance of Psychodopygus davisi as a vector of zoonotic cutaneous leishmaniasis. Memórias do Instituto Oswaldo Cruz, 98, 751-755.

14. Grimaldi G Jr, Momen H, Naiff RD, McMahon-Pratt D, Barrett TV. 1991. Characterization and classification of leishmanial parasites from humans, wild mammals, and sand flies in the Amazon region of Brazil. American Journal of Tropical Medicine and Hygiene, 44, 645-661.

15. Guizani I, Mukhtar M, Abderrazak SB, Alvar J, Shaw J. 2011. Leishmaniases, in Encyclopedia of Environmental Health. Nriagu JO, Editor. Elsevier: Burlington. p. 453-480.

16. Jennings YL, de Souza AAA, Ishikawa EA, Shaw J, Lainson R, Silveira FT. 2014. Phenotypic characterization of Leishmania spp. causing cutaneous leishmaniasis in the lower Amazon region, western Pará state, Brazil, reveals a putative hybrid parasite, Leishmania (Viannia) guyanensis x Leismania (Viannia) shawi shawi. Parasite, 21, 39.

17. Killick-Kendrick R, Ward RD. 1981. Third European Multicolloquium of Parasitology. Workshop no. 11. Ecology of Leishmania. Parasitology, 82, 143-152.

18. Lainson R. 2010. The Neotropical Leishmania species: a brief historical review of their discovery, ecology and taxonomy. Revista Pan-Amazônica de Saúde, 1, 13-32.

19. Lainson R, Shaw JJ. 1989. Leishmania (Viannia) naiffi sp. n., a parasite of the armadillo, Dasypus novemcinctus in Amazonian Brazil. Annales de Parasitologie Humaine et Comparée, 64, 3-9. 
20. Lainson R, Shaw JJ, Ward RD, Fraiha H. 1973. Leishmaniasis in Brazil. IX. Considerations on the Leishmania braziliensis complex. Importance of sand flies of the genus Psychodopygus (Mangabeira) in the transmission of Leishmania braziliensis braziliensis in North Brazil. Transactions of the Royal Society of Tropical Medicine and Hygiene, 67, 184-196.

21. Lainson R, Ward RD, Shaw JJ. 1976. Cutaneous leishmaniasis in north Brazil: Lutzomyia anduzei as a major vector. Transactions of the Royal Society of Tropical Medicine and Hygiene, 70, 171-172.

22. Lainson R, Shaw JJ, Ready PD, Miles MA, Póvoa MM. 1981. Leishmaniasis in Brazil: XVI. Isolation and identification of Leishmania species from sand flies, wild mammals and man in north Pará State, with particular reference to Leishmania braziliensis guyanensis causative agent of "pian-bois". Transactions of the Royal Society of Tropical Medicine and Hygiene, $75,530-536$.

23. Lainson R, Braga RR, De Souza AA, Póvoa MM, Ishikawa EA, Silveira FT. 1989. Leishmania (Viannia) shawi sp. n., a parasite of monkeys, sloths and procyonids in Amazonian Brazil. Annales de Parasitologie Humaine et Comparée, 64, 200-207.

24. Lainson R, Shaw JJ, Silveira FT, Braga RR, Ishikawa EAY. 1990. Cutaneous leishmaniasis of man due to Leishmania (Viannia) naiffi Lainson \& Shaw 1989. Annales de Parasitologie Humaine et Comparée, 65, 282-284.

25. Lainson R, Shaw JJ, Souza AA, Silveira FT, Falqueto A. 1992. Further observations on Lutzomyia ubiquitalis (Psychodidae: Phlebotominae), the sandfly vector of Leishmania (Viannia) lainsoni. Memórias do Instituto Oswaldo Cruz, 87, 437-439.

26. Marcondes CB. 2007. A proposal of generic and subgeneric abbreviations for Phlebotomine Sandflies (Diptera: Psycodidae: Phlebotominae) of the World. Entomology News, 118, 351-356.

27. Miles MA, Póvoa MM, Souza AA, Lainson R, Shaw JJ. 1980. Some methods for the enzymic characterization of LatinAmerican Leishmania with particular reference to Leishmania mexicana amazonensis and subspecies of Leishmania hertigi. Transactions of the Royal Society of Tropical Medicine and Hygiene, 74, 243-252.

28. Naiff RD, Freitas RA, Naiff MF, Arias JR, Barret TV, Momen H, Grimaldi Jr G . 1991. Epidemiological and nosological aspects of Leishmania (V.) naiffi Lainson \& Shaw, 1989. Memórias do Instituto Oswaldo Cruz, 86, 317-211.

29. Rangel EF, Lainson R. 2009. Proven and putative vectors of American cutaneous leishmaniasis in Brazil: aspects of their biology and vectorial competence. Memórias do Instituto Oswaldo Cruz, 104, 937-95.

30. Rangel EF, Ryan L, Lainson R, Shaw JJ. 1985. Observations on the sand fly (Diptera: Psychodidae) fauna of Além Paraiba, State of Minas Gerais, Brazil, and the isolation of a parasite of the Leishmania braziliensis complex from Psychodopygus hirsuta hirsuta. Memórias do Instituto Oswaldo Cruz, 80, 373-374.

31. Ready P. 2013. Biology of phlebotomine sand flies as vectors of disease agents. Annual Review of Entomology, 58, 227-250.

32. Ready PD, Lainson R, Shaw JJ. 1984. Habitat and seasonality of Psychodopygus wellcomei help incriminate it as a vector of Leishmania braziliensis in Amazonia and northeast Brazil. Transactions of the Royal Society of Tropical Medicine and Hygiene, 78, 543-544.

33. Ready PD, Lainson R, Shaw JJ, Ward RD. 1986. The ecology of Lutzomyia umbratilis Ward \& Fraiha (Diptera Pyschodidae), the major vector to man of Leishmania braziliensis guyanensis Floch in northeast Amazonian Brazil. Bulletin of Entomological Research, 76, 21-40.

34. Roberts DR, Hsi BP. 1979. An index of species abundance for use with mosquito surveillance data. Environmental Entomology, 8, 1007-1013.

35. Ryan L, Lainson R, Shaw JJ. 1987. Leishmaniasis in Brazil. XXIV. Natural flagellate infections of sand flies (Diptera: Psychodidae) in Pará State, with particular reference to the role of Psychodopygus wellcomei as the vector of Leishmania braziliensis braziliensis in the Serra dos Carajás. Transactions of the Royal Society of Tropical Medicine and Hygiene, 81, 353-359.

36. Silveira FT, Souza AA, Lainson R, Shaw JJ, Braga RR, Ishikawa EE. 1991. Cutaneous leishmaniasis in the Amazon region: natural infection of the sandfly Lutzomyia ubiquitalis (Psychodidae: Phlebotominae) by Leishmania (Viannia) lainsoni in Pará State, Brazil. Memórias do Instituto Oswaldo Cruz, $86,127-130$

37. Silveira FT, Lainson R, Corbett CEP. 2004. Clinical and immunopathological spectrum of American cutaneous leishmaniasis with special reference to the disease in Amazonian Brazil. Memórias do Instituto Oswaldo Cruz, 99, 239-251.

38. Silveira FT, Lainson R, Gomes CMC, Laurenti MD, Corbett CEP. 2009. Immunopathogenic competences of Leishmania (V.) braziliensis and $L$. (L.) amazonensis in American cutaneous leishmaniasis. Parasite Immunology, 31, 423-431.

39. Silveira FT, Lainson R, Muller SFR, Souza AAA, Corbett CEP. 2013. Leishmaniose tegumentar americana, in Medicina Tropical e Infectologia na Amazônia, Leão RNG, Editor. Samauma, 2nd ed., Vol. 2, Instituto Evandro Chagas: Belém, Pará, Brasil. p. $1203-1244$.

40. Silveira FT, Lainson R, Muller SFR, Gomes CMC, Laurenti MD, Corbett CEP. 2014. Leishmaniose tegumentar americana, in Tratado de Dermatologia, Belda Jr W, Di Chiacchio N, Criado PR, Editors. 2nd ed., Vol. 1, Atheneu: São Paulo, Brasil. p. $1453-1482$.

41. Soares ES. 2004. Desafios, resultados, ameaças e oportunidades em uma unidade de conservação na Amazônia: A Floresta Nacional do Tapajós. Ibama-ProManejo: Manaus, $161 \mathrm{p}$.

42. Shaw JJ. 1999. The relationship of sand fly ecology to the transmission of leishmaniasis in South America with particular reference to Brazil, in Contributions to the knowledge of Diptera, Burger J, Editor. vol. 14, Associated Publishers: Gaisnville, Florida. p. 503-517.

43. Shaw JJ, Lainson R. 1972. Leishmaniasis in Brazil. VI. Observations on the seasonal variations of Lutzomyia flaviscutellata in different types of forest and its relationship to enzootic rodent leishmaniasis (Leishmania mexicana amazonensis). Transactions of the Royal Society of Tropical Medicine and Hygiene, 66, 709-717.

44. Shaw JJ, Ishikawa EAY, Lainson R. 1989. A rapid and sensitive method for the identification of Leishmania with monoclonal antibodies using fluorescein-labelled avidin. Transactions of the Royal Society of Tropical Medicine and Hygiene, 83, 783-784.

45. Souza A, Ishikawa E, Braga R, Silveira F, Lainson R, Shaw J. 1996. Psychodopygus complexus, a new vector of Leishmania braziliensis to humans in Pará State, Brazil. Transactions of the Royal Society of Tropical Medicine and Hygiene, 90, 112-113.

46. Souza AAA, Silveira FT, Lainson R, Barata IR, Silva MGS, Lima JAN, Pinheiro MSB, Silva FMM, Vasconcelos LS, Campos MB, Ishikawa EAY. 2010. The Phlebotominae fauna of Serra dos Carajás, Pará, Brazil, and its possible implication 
in the transmission of American tegumentary leishmaniasis. Revista Pan-Amazônica de Saúde, 1, 45-51.

47. Valderrama A, Tavares MG, Andrade Filho JD. 2011. Anthropogenic influence on the distribution, abundance and diversity of sandfly species (Diptera: Phlebotominae: Psychodidae), vectors of cutaneous leishmaniasis in Panama. Memórias do Instituto Oswaldo Cruz, 106, 1024-1031.

48. Walters LL, Chaplin GL, Modi GB, Tesh RB. 1989. Ultrastructural biology of Leishmania (Viannia) panamensis (=Leishmania braziliensis panamensis) in Lutzomyia gomezi (Diptera: Psychodidae): natural host-parasite association. American Journal of Tropical Medicine and Hygiene, 40, 19-39.
49. Walton BC, Shaw JJ, Lainson R. 1977. Observations on the in vitro cultivation of Leishmania braziliensis. Journal of Parasitology, 63, 1118-1119.

50. Ward RD, Fraiha H. 1977. Lutzomyia umbratilis n. sp. A sandfly previously identified as L. anduzei (Rozeboom, 1942) (Diptera: Psychodidae). Journal of Medical Entomology, 14, 313-317.

51. Young DG, Duncan MA. 1994. Guide to the Identification and Geographic Distribution of Lutzomyia Sand Flies in Mexico, the West Indies, Central and South America (Diptera: Psychodidae). Memoirs of the American Entomological Institute 54, Associated Publishers: Gainesville, 881 p.

Cite this article as: de Souza AAA, dos Santos TV, Jennings YLL, Ishikawa EAY, Barata IR, Silva MGS, Lima JAN, Shaw J, Lainson R \& Silveira FT: Natural Leishmania (Viannia) spp. infections in phlebotomine sand flies (Diptera: Psychodidae) from the Brazilian Amazon region reveal new putative transmission cycles of American cutaneous leishmaniasis. Parasite, 2016, 23, 22.

\section{-0 PARASTE}

An international open-access, peer-reviewed, online journal publishing high quality papers on all aspects of human and animal parasitology

Reviews, articles and short notes may be submitted. Fields include, but are not limited to: general, medical and veterinary parasitology; morphology, including ultrastructure; parasite systematics, including entomology, acarology, helminthology and protistology, and molecular analyses; molecular biology and biochemistry; immunology of parasitic diseases; host-parasite relationships; ecology and life history of parasites; epidemiology; therapeutics; new diagnostic tools.

All papers in Parasite are published in English. Manuscripts should have a broad interest and must not have been published or submitted elsewhere. No limit is imposed on the length of manuscripts.

Parasite (open-access) continues Parasite (print and online editions, 1994-2012) and Annales de Parasitologie Humaine et Comparée (1923-1993) and is the official journal of the Société Française de Parasitologie. 